\title{
Bafilomycins produced by an endophytic actinomycete Streptomyces sp. YIM56209
}

\author{
Zhiguo Yu ${ }^{1,2}$, Li-Xing Zhao ${ }^{3}$, Cheng-Lin Jiang ${ }^{3}$, Yanwen Duan ${ }^{2}$, Lily Wong ${ }^{4}$, Kristopher C Carver ${ }^{4}$, \\ Linda A Schuler ${ }^{4}$ and Ben Shen ${ }^{1,5,6}$
}

The Journal of Antibiotics (2011) 64, 159-162; doi:10.1038/ja.2010.147; published online 24 November 2010

Keywords: bafilomycins; cytotoxicity; endophytic actinomycete; Streptomyces sp. YIM56209

Bafilomycins (Figure 1), macrolide antibiotics with a 16-membered lactone ring as their defining structural scaffold, are produced by a variety of streptomycetes. ${ }^{1-5}$ These macrolides exhibit a variety of biological activities, including antitumor, ${ }^{6}$ antifungal, ${ }^{7}$ antiparasitic ${ }^{8}$ and immunosuppressant activities. ${ }^{9}$ In particular, bafilomycin A1 is an extremely potent and specific inhibitor of the vacuolar ATPases ${ }^{10}$ and has also been found to inhibit the release of $\beta$-amyloid ${ }^{11}$ and mitogeninduced DNA synthesis. ${ }^{12}$ These features provide only a few examples of biological activities that have drawn considerable interest to the bafilomycins.

In our on-going effort to search for new and biologically active secondary metabolites produced by actinomycetes from unexplored and underexplored ecological niches, ${ }^{13-16}$ an endophytic actinomycete Streptomyces sp. YIM56209 was isolated from a healthy stem of Drymaria cordata. Initial screening of the crude extract showed potent cytotoxicity against selected cancer cell lines as well as moderate inhibitory effect on prolactin (PRL)-initiated phosphorylation of ERK1/2 in MCF-7 breast cancer cells. Large-scale fermentation and subsequent fractionation of the crude extract led to the isolation of two new bafilomycins, named 9-hydroxybafilomycin D (1) and 29hydroxybafilomycin D (2), together with nine known bafilomycins identified as bafilomycin D (3), ${ }^{3}$ bafilomycin E (4), ${ }^{3}$ bafilomycin A1 (5), ${ }^{1}$ bafilomycin B1 (6), ${ }^{1,7}$ bafilomycin B2 (7), ${ }^{1}$ bafilomycin $\mathrm{C} 1(8),{ }^{1}$ bafilomycin C2 (9), ${ }^{1}$ bafilomycin C1 amide (10) ${ }^{17}$ and bafilomycin C2 amide (11) $)^{17}$ (Figure 1). The structures of $\mathbf{1}$ and $\mathbf{2}$ were established by comprehensive spectroscopic analyses, whereas the structures of 3-11 were confirmed by comparing their ${ }^{1} \mathrm{H}$ and ${ }^{13} \mathrm{C}$ NMR data with those in the literature. We present herein the isolation, structural elucidation and bioactivity assessment of these new and known bafilomycins.

The ethyl acetate extract of the Streptomyces sp. YIM56209 culture was subjected to sequential silica gel and Sephadex LH-20 chromatography, followed by further purification with reversed-phase HPLC to give 11 bafilomycins (1-11) (Figure 1).

Compound 1 was isolated as a white amorphous powder. Highresolution MALDI-FTMS analysis of $\mathbf{1}$ afforded an $[\mathrm{M}+\mathrm{Na}]^{+}$ion at $m / z$ 643.38197, consistent with a molecular formula of $\mathrm{C}_{35} \mathrm{H}_{56} \mathrm{O}_{9}$ (calculated $[\mathrm{M}+\mathrm{Na}]^{+}$ion at $\mathrm{m} / z$ 643.38165), which contained an extra oxygen atom in comparison with the molecular formula of 3 $\left(\mathrm{C}_{35} \mathrm{H}_{56} \mathrm{O}_{8}\right)$. The ${ }^{13} \mathrm{C}$ NMR spectrum of $\mathbf{1}$ (Table 1) shows 34 signals, representative of 35 carbons (two, C-7 and C-23, have the same chemical shift at $\left.\delta_{\mathrm{C}} 80.0\right)$. In conjunction with the gHMQC spectrum, the presence of two methoxy groups $\left(2-\mathrm{OCH}_{3}\right.$ and $\left.14-\mathrm{OCH}_{3}\right)$, nine Me groups (C-25, C-26, C-27, C-28, C-29, C-30, C-31, C-32 and C-33), six methine carbons (C-6, C-8, C-16, C-18, C-22 and C-24), seven olefinic carbons (C-3, C-5, C-11, C-12, C-13, C-20 and C-21), six oxymethine carbons (C-7, C-9, C-14, C-15, C-17 and C-23), three olefinic quaternary carbons (C-2, C-4 and C-10) and two carbonyl groups (C-1 and C-19) was confirmed (Table 1 and Figure 1). Compared with a similar data set obtained from 3 (Supplementary Tables S1 and S2), the shift of the methylene carbon signal $\left(\delta_{\mathrm{C}} 41.6\right.$ at C-9 of 3$)$ to the oxygenated methine signal $\left(\delta_{\mathrm{C}} 77.2\right.$ at C-9 of $\left.\mathbf{1}\right)$, together with its MS data, suggested that 1 was likely a C-9 hydroxylated congener of 3 . This conclusion was further supported by gHMBC correlation of $\mathrm{H}-9\left(\delta_{\mathrm{H}} 3.85\right)$ with C-7 $\left(\delta_{\mathrm{C}} 80.0\right), \mathrm{C}-11\left(\delta_{\mathrm{C}}\right.$ $125.5), \mathrm{C}-28\left(\delta_{\mathrm{C}} 18.2\right)$ and C-29 $\left(\delta_{\mathrm{C}} 18.8\right)$ (Figure 2$)$. Accordingly, 1 was finally established as 9-hydroxybafilomycin $\mathrm{D}$ with the stereochemistry of C-9 remaining undetermined because of the limited quantities of compound presently available (Figure 1).

Compound 2 was isolated as a white amorphous powder. The molecular formula of $\mathbf{2}$ was also determined by high-resolution MALDI-FTMS analysis, which yielded an $[\mathrm{M}+\mathrm{Na}]^{+}$ion at $\mathrm{m} / \mathrm{z}$ 643.38151, consistent with a molecular formula of $\mathrm{C}_{35} \mathrm{H}_{56} \mathrm{O}_{9}$

${ }^{1}$ Division of Pharmaceutical Sciences, School of Pharmacy, University of Wisconsin-Madison, Madison, WI, USA; ${ }^{2}$ Hunan Engineering Research Center of Combinatorial Biosynthesis and Natural Product Drug Discovery, Hunan, China; ${ }^{3}$ Yunnan Institute of Microbiology, Yunnan University, Yunnan, China; ${ }^{4}$ Department of Comparative Biosciences, University of Wisconsin-Madison, Madison, WI, USA; ${ }^{5}$ University of Wisconsin National Cooperative Drug Discovery Group, University of Wisconsin-Madison, Madison, WI, USA and ${ }^{6}$ Department of Chemistry, University of Wisconsin-Madison, Madison, WI, USA

Correspondence: Dr B Shen, Division of Pharmaceutical Sciences, School of Pharmacy, University of Wisconsin-Madison, 777 Highland Avenue, Madison, WI 53705-2222, USA. E-mail: bshen@pharmacy.wisc.edu

Dedicated to late Professor C Richard 'Dick'/'Hutch' Hutchinson, for his exceptional contributions to natural product biosynthesis, engineering and drug discovery.

Received 21 September 2010; revised 1 November 2010; accepted 2 November 2010; published online 24 November 2010 


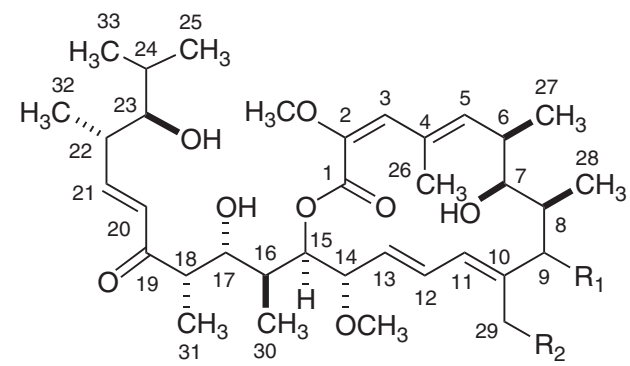

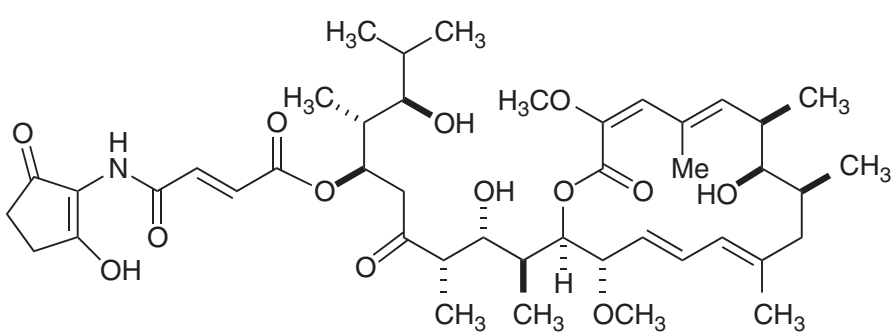

Bafilomycin E (4)

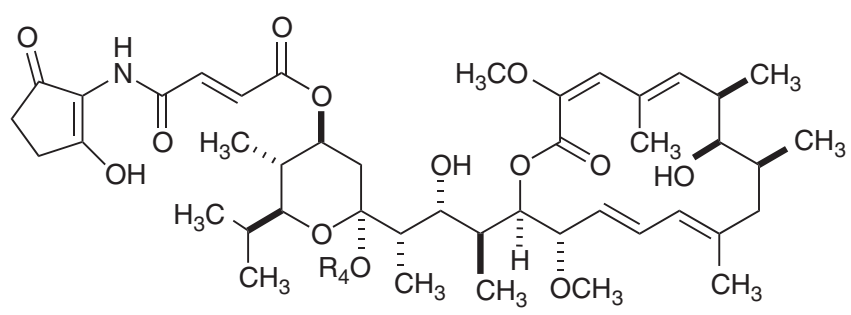

Bafilomycin B1 $\left(6, \mathrm{R}_{4}=\mathrm{H}\right)$

Bafilomycin B2 $\left(7 \mathrm{R}_{4}=\mathrm{CH}_{3}\right)$
9-Hydroxybafilomycin D (1, $\left.\mathrm{R}_{1}=\mathrm{OH}, \mathrm{R}_{2}=\mathrm{H}\right)$

29-Hydroxybafilomycin $\mathrm{D}\left(2, \mathrm{R}_{1}=\mathrm{H}, \mathrm{R}_{2}=\mathrm{OH}\right)$

Bafilomycin $D\left(\mathbf{3}, \mathrm{R}_{1}=\mathrm{R}_{2}=\mathrm{H}\right)$

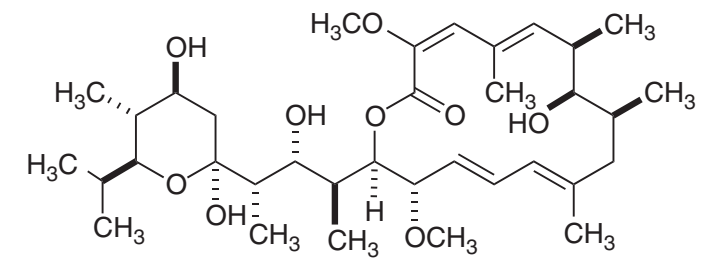

Bafilomycin A1 (5)

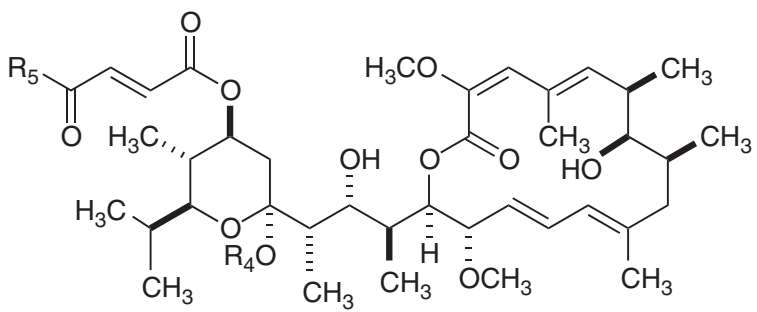

Bafilomycin C1 (8 $\left.\mathrm{R}_{4}=\mathrm{H}, \mathrm{R}_{5}=\mathrm{OH}\right)$

Bafilomycin C2 (9 $\left.\mathrm{R}_{4}=\mathrm{CH}_{3}, \mathrm{R}_{5}=\mathrm{OH}\right)$

Bafilomycin $\mathrm{C} 1$ amide $\left(\mathbf{1 0} \mathrm{R}_{4}=\mathrm{H}, \mathrm{R} 5=\mathrm{NH}_{2}\right)$

Bafilomycin $\mathrm{C} 2$ amide $\left(11 \mathrm{R}_{4}=\mathrm{CH}_{3}, \mathrm{R}_{5}=\mathrm{NH}_{2}\right)$

Figure 1 Structures of new (1 and 2) and known (3-11) bafilomycins isolated from Streptomyces sp. YIM56209.

(calculated $[\mathrm{M}+\mathrm{Na}]^{+}$ion at $\mathrm{m} / z$ 643.38165). The ${ }^{1} \mathrm{H}$ and ${ }^{13} \mathrm{C} \mathrm{NMR}$ data (Table 1) of $\mathbf{2}$ were similarly compared with those of $\mathbf{3}$ as well as $\mathbf{2}$ (Supplementary Tables S1 and S2), and the shift of the Me group signal [ $\delta_{\mathrm{C}} 20.2$ and $\delta_{\mathrm{H}} 1.91(\mathrm{~s})$ at C-29 of 3 ] to the oxymethylene signal [ $\delta_{\mathrm{C}} 63.1$ and $\delta_{\mathrm{H}} 4.58(\mathrm{~d}), 4.07(\mathrm{~d})$ at C-29 of 2], together with its MS data, readily established that 2 is most likely a C-29 hydroxylated analog of 3. This conclusion was further supported by gHMBC correlations of $\mathrm{H}_{2}-29\left[\delta_{\mathrm{H}} 4.58(\mathrm{~d}), 4.07(\mathrm{~d})\right]$ with $\mathrm{C}-9\left(\delta_{\mathrm{C}} 36.5\right)$, C-10 $\left(\delta_{\mathrm{C}} 143.7\right)$ and C-11 $\left(\delta_{\mathrm{C}} 128.1\right), \mathrm{H}-11\left[\delta_{\mathrm{H}} 5.90(\mathrm{~d})\right]$ with C-29 $\left(\delta_{\mathrm{C}} 63.1\right)$, and $\mathrm{H}_{2}-9\left[\delta_{\mathrm{H}} 2.30(\mathrm{~m}), 2.10(\mathrm{~m})\right]$ with $\mathrm{C}-29\left(\delta_{\mathrm{C}} 63.1\right)$ (Figure 2). Thus, the structure of 2 was deduced to be 29-hydroxybafilomycin D (Figure 1).

The extreme cytotoxicity of the bafilomycins has limited their practical utility as both molecular probes and potential therapeutics. We therefore assessed the cytotoxicity of the two new bafilomycin analogs (1 and 2) together with the nine known ones (3-11) using A-549 human lung adenocarcinoma and HT-29 human colorectal adenocarcinoma cancer cell lines. Although 3-11 exhibited potent cytoxicity in general, under the conditions tested, the two new analogs $\mathbf{1}$ and $\mathbf{2}$ are, on average, two to three orders of magnitude less toxic, a property that could potentially be explored for the utilities of bafilomycin family (Table 2 ).

The ability of $\mathbf{5}$ to inhibit vacuolar-type $\mathrm{H}^{+}$-ATPases, resulting in reduced acidification of sorting endosomes and subsequent interference with post-internalization receptor trafficking, is wellestablished. ${ }^{10,18}$ In light of the links between trafficking and signal transduction for many receptors, ${ }^{19}$ we attempted to probe the effect of 1-11 on phosphorylation of the mitogen-activated protein kinases, ERK1/2, initiated by two well-characterized breast cancer mitogens, $\mathrm{PRL}^{20}$ and epidermal growth factor (EGF), ${ }^{21}$ in the breast cancer cell line MCF-7. As summarized in Table 2, the relative activities of bafilomycin family members in this assay differed substantially. None of the bafilomycins tested was able to reduce EGF-initiated signals, although 4 slightly amplified these signals. The relative lack of activity in this assay resembles the failure of bafilomycin to inhibit EGF signals to $c$-fos in fibroblasts, despite inhibition of EGF-induced mitosis. ${ }^{12}$ In contrast, six of the analogs, 2, 3, 5, 6, 7 and 10, were able to reduce PRL-mediated signals to ERK1/2; 10 displayed optimum activity with an $\mathrm{IC}_{50}$ of $\sim 12 \mu \mathrm{M}$. The relative specificity of bafilomycins for PRL signaling pathway inhibition, compared with EGF, may reflect differences in receptor trafficking or other biological actions of these compounds; the susceptibility of receptor trafficking to reduced acidification has been reported to vary among cell types. ${ }^{22}$

In summary, we have isolated two new bafilomycin analogs, 9-hydroxybafilomycin D (1) and 29-hydroxy-bafilomycin D (2), together with nine known bafilomycin congeners (3-11) from fermentation culture of the endophyte actinomycete Streptomyces sp. YIM56209 (Figure 1). The structures of 1 and $\mathbf{2}$ were elucidated by MS 
and NMR techniques. Hydroxylation at either the C-9 or C-29 positions of 3, both integral components of the 16-membered lactone scaffold, profoundly impacts the biological activity of $\mathbf{1}$ and $\mathbf{2}$ relative to 3 , as well as other previously known bafilomycins. For example, 1 was found to be $\sim 5000$ times less cytotoxic to A549 cells and $\sim 4000$

Table 1 Summary of ${ }^{1} \mathrm{H}$ and ${ }^{13} \mathrm{C}$ NMR spectroscopic data for 1 and 2 (in $\mathrm{CDCl}_{3}$ )

\begin{tabular}{|c|c|c|c|c|}
\hline \multirow[b]{2}{*}{ Position } & \multicolumn{2}{|l|}{$1(\mathrm{~J}$ in $\mathrm{Hz})$} & \multicolumn{2}{|l|}{$2(\mathrm{~J}$ in $\mathrm{Hz})$} \\
\hline & $\delta_{H}$ mult & $\delta_{c}$ & $\delta_{H}$ mult & $\delta_{c}$ \\
\hline 1 & - & 166.7 & - & 166.4 \\
\hline 2 & - & 141.8 & - & 141.6 \\
\hline 3 & 6.63 (s) & 133.2 & $6.60, \mathrm{~s}$ & 132.6 \\
\hline 4 & - & 133.4 & - & 133.2 \\
\hline 5 & $5.73, \mathrm{~d}(9.0)$ & 141.0 & $5.81, d(9.0)$ & 142.1 \\
\hline 6 & $2.54, \mathrm{~m}$ & 37.2 & $2.54, \mathrm{~m}$ & 36.6 \\
\hline 7 & $3.41, \mathrm{~d}(7.0)$ & 80.0 & $3.43, d(7.0)$ & 81.4 \\
\hline 8 & $2.31, \mathrm{~m}$ & 38.8 & $1.91, \mathrm{~m}$ & 40.6 \\
\hline 9 & $3.85, \mathrm{~d}(10.5)$ & 77.2 & $2.30, \mathrm{~m} ; 2.10, \mathrm{~m}$ & 36.5 \\
\hline 10 & - & 147.2 & - & 143.7 \\
\hline 11 & $6.02, \mathrm{~d}(10.5)$ & 125.5 & $5.90, \mathrm{~d}(11.0)$ & 128.1 \\
\hline 12 & $6.51, \mathrm{dd}(14.5,11.0)$ & 133.3 & $6.64, \mathrm{dd}(15.0,11.0)$ & 132.0 \\
\hline 13 & $5.29, \mathrm{dd}(15.0,9.5)$ & 130.5 & $5.23, \mathrm{dd}(15.0,9.5)$ & 129.5 \\
\hline 14 & $3.81, \mathrm{dd}(8.5,8.0)$ & 83.4 & $3.81, \mathrm{dd}(8.5,8.0)$ & 83.0 \\
\hline 15 & $5.05, d(8.5)$ & 76.7 & $5.05, d(9.0)$ & 76.2 \\
\hline 16 & $2.06, \mathrm{~m}$ & 38.8 & $2.07, \mathrm{~m}$ & 38.3 \\
\hline 17 & $3.77, \mathrm{~m}$ & 72.9 & $3.76, \mathrm{~m}$ & 72.2 \\
\hline 18 & 2.97, m & 46.6 & 2.97, m & 46.4 \\
\hline 19 & - & 203.4 & - & 203.0 \\
\hline 20 & $6.28, d(16.0)$ & 129.6 & $6.29, d(16.0)$ & 129.3 \\
\hline 21 & $6.90, \mathrm{dd}(15.5,8.0)$ & 148.9 & $6.90, \mathrm{dd}(16.0,8.0)$ & 148.5 \\
\hline 22 & $2.54, \mathrm{~m}$ & 40.3 & $2.52, \mathrm{~m}$ & 40.0 \\
\hline 23 & $3.18, \mathrm{t}(6.0)$ & 80.0 & $3.18, \mathrm{t}(6.0)$ & 79.8 \\
\hline 24 & $1.72, \mathrm{~m}$ & 31.2 & $1.73, \mathrm{~m}$ & 30.9 \\
\hline 25 & $0.92, d(7.0)$ & 17.0 & $0.93, d(7.0)$ & 16.8 \\
\hline 26 & $1.98, \mathrm{~s}$ & 14.2 & $1.98, \mathrm{~s}$ & 14.1 \\
\hline 27 & $1.07, d(7.0)$ & 17.4 & $1.07, d(7.0)$ & 17.0 \\
\hline 28 & $0.95, \mathrm{~d}(7.0)$ & 18.2 & $0.97, \mathrm{~d}(7.0)$ & 22.0 \\
\hline 29 & $2.03, \mathrm{~s}$ & 18.8 & $4.58, d(12.5) ; 4.07, d(12.5)$ & 63.1 \\
\hline 30 & $0.95, d(7.0)$ & 10.9 & $0.95, d(7.0)$ & 10.6 \\
\hline 31 & $1.21, \mathrm{~d}(7.0)$ & 10.6 & $1.21, d(7.0)$ & 10.2 \\
\hline 32 & $1.08, \mathrm{~d}(6.5)$ & 16.9 & $1.08, \mathrm{~d}(6.5)$ & 16.6 \\
\hline 33 & $0.95, d(7.0)$ & 19.9 & $0.95, d(7.0)$ & 19.7 \\
\hline $2-\mathrm{OCH}_{3}$ & $3.68, \mathrm{~s}$ & 60.5 & $3.67, \mathrm{~s}$ & 60.1 \\
\hline $14-\mathrm{OCH}_{3}$ & $3.22, \mathrm{~s}$ & 56.0 & $3.21, \mathrm{~s}$ & 55.8 \\
\hline
\end{tabular}

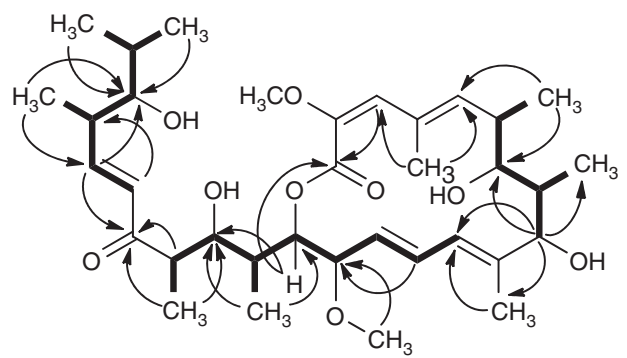

COSY $\mathrm{HMBC}$ times less toxic to HT-29 cells than 3 , whereas 2 was found to be $\sim 3000$ times less cytotoxic to A549 cells and $\sim 1500$ times less toxic to HT-29 cells relative to 3 . As the bafilomycins are unable to be used clinically because of their fatal toxicity, ${ }^{10}$ this discovery opens a new path for the practical application of bafilomycins. Moreover, the ability to inhibit PRL-mediated signaling pathways may be useful as few reagents are available to probe the activities of this hormone/ cytokine in normal physiology and pathology, including breast cancer.

\section{EXPERIMENTAL SECTION}

Optical rotations were measured in $\mathrm{CHCl}_{3}$ on a Perkin-Elmer 241 instrument (Perkin-Elmer, Waltham, MA, USA) at the sodium D line $(589 \mathrm{~nm}) .{ }^{1} \mathrm{H}$ and ${ }^{13} \mathrm{C}$ NMR spectra were recorded at $25^{\circ} \mathrm{C}$ on a Varian Unity Inova 500 instrument (Agilent Technologies, Inc., Santa Clara, CA, USA) operating at $500 \mathrm{MHz}$ for ${ }^{1} \mathrm{H}$ and $125 \mathrm{MHz}$ for ${ }^{13} \mathrm{C}$ nuclei. High-resolution mass spectral analyses were acquired on an IonSpec HiResMALDI FT-MS with a 7 T superconducting magnet (IonSpec, Inc., Lake Forest, CA, USA). Semi-preparative HPLC was performed on a Varian HPLC system with an Alltima C18 column $(5 \mu, 10.0 \times 250 \mathrm{~mm}$, Alltech Associates, Inc., Deerfield, IL, USA). Column chromatography was performed either on silica gel (230-400 mesh, Natland International, Research Triangle Park, NC, USA), or Sephadex LH-20 (Pharmacia, Kalamazoo, MI, USA). Chemical regents were purchased from Sigma-Aldrich Corporation (St Louis, MO, USA).

The producing stain YIM56209 was isolated from a healthy stem of traditional Chinese medicinal plant D. cordata from Xishuangbanna, Yunnan, China, which was used to treat hepatitis and nephritis, and was identified as Streptomyces sp. using a polyphasic taxonomy approach. Pure strain was permanently stored in $50 \%$ glycerol at $-80^{\circ} \mathrm{C}$. The fermentation medium consisted of $2.0 \mathrm{~g}$ yeast extract, $5.0 \mathrm{~g}$ malt extract and $2.0 \mathrm{~g}$ dextrose in 1.01 Milli-Q water (Millipore Corporation, Billerica, MA, USA), $\mathrm{pH}$ 7.2. A three-stage fermentation procedure was adopted: (1) seed culture in $10 \mathrm{ml}$ medium at $28^{\circ} \mathrm{C}$ for 4 days, (2) $1.0 \mathrm{ml}$ of the resultant culture as inoculum to $50 \mathrm{ml}$ medium in 250 -ml Erlenmeyer flasks at $28^{\circ} \mathrm{C}$ for 3 days and (3) $20 \mathrm{ml}$ the resultant culture as inoculum to $400 \mathrm{ml}$ medium in 2.0-1 Erlenmeyer flasks at $28^{\circ} \mathrm{C}$ for 7 days, all on a rotary shaker at 250 r.p.m.

A total of 9.61 of fermentation culture was collected and extracted with ethyl acetate. The combined extracts were concentrated under reduced pressure to give the crude residue ( $3.1 \mathrm{~g}$ ), which was subjected to silica gel chromatography eluted with a hexane-ethyl acetate gradient $(0-100 \%)$. Six fractions, A-F, were monitored by TLC analysis and collected. Fraction E $(103 \mathrm{mg})$ was further chromatographed over Sephadex LH-20 column and eluted with $\mathrm{MeOH}$ to give three subfractions E1-E3. Subfraction E2 was finally purified by semi-preparative HPLC to afford $\mathbf{1}(1.0 \mathrm{mg}), \mathbf{2}(1.9 \mathrm{mg}), \mathbf{4}(2.1 \mathrm{mg}), \mathbf{1 0}(1.5 \mathrm{mg}), \mathbf{8}$ $(1.8 \mathrm{mg}), \mathbf{1 1}(2.1 \mathrm{mg})$ and $\mathbf{9}(2.4 \mathrm{mg})$. Similarly, $\mathbf{3}(11.3 \mathrm{mg})$ and $\mathbf{5}(9.8 \mathrm{mg})$ were obtained from fraction C $(260 \mathrm{mg})$ and $6(12.8 \mathrm{mg})$ and $7(21.2 \mathrm{mg})$ were obtained from fraction D $(271 \mathrm{mg})$.

9-hydroxybafilomycin (1): white amorphous powder; $[\alpha]_{\mathrm{D}}^{20}-27.6^{\circ}$ (c 0.17 , $\left.\mathrm{CHCl}_{3}\right) ; \mathrm{UV}(\mathrm{MeOH}) \lambda_{\max } \mathrm{nm}, 285$ and $246 ;{ }^{1} \mathrm{H} \mathrm{NMR}\left(500 \mathrm{MHz}, \mathrm{CDCl}_{3}\right)$ and ${ }^{13} \mathrm{C}$ NMR ( $125 \mathrm{MHz}, \mathrm{CDCl}_{3}$ ), see Table 1; MALDI-FTMS (positive ion), $[\mathrm{M}+\mathrm{Na}]^{+}$ion at $m / z 643.38197$ for $\mathrm{C}_{35} \mathrm{H}_{56} \mathrm{O}_{9}$ (calcd for $\left.[\mathrm{M}+\mathrm{Na}]^{+}, 643.38165\right)$.

29-hydroxybafilomycin (2): white amorphous powder; $[\alpha]_{\mathrm{D}}^{20}-17.7^{\circ}$ (c 0.13 , $\left.\mathrm{CHCl}_{3}\right) ; \mathrm{UV}(\mathrm{MeOH}) \lambda_{\max } \mathrm{nm}, 285$ and $246 ;{ }^{1} \mathrm{H} \mathrm{NMR}\left(500 \mathrm{MHz}, \mathrm{CDCl}_{3}\right)$ and

Figure 2 Key HMBC and H, H-COSY correlations for the two new bafilomycin congeners $\mathbf{1}$ and 2. 
Table 2 Summary of biological activities for 1 and 2 in comparison with 3-11

\begin{tabular}{|c|c|c|c|c|}
\hline \multirow[b]{2}{*}{ Compound } & \multicolumn{2}{|c|}{ Cytotoxicity (IC 50 in nm unless otherwise noted) } & \multicolumn{2}{|c|}{ Inhibition of ERK1/2 phosphorylation $\left(I C_{50}\right.$ in $\mu \mathrm{M}^{\circledR}$} \\
\hline & A549 & HT29 & EGF mediated & PRL mediated \\
\hline 2 & $3900 \pm 200$ & $3400 \pm 100$ & $N A^{b}$ & 31.6 \\
\hline 3 & $1.3 \pm 0.5$ & $2.2 \pm 0.4$ & $N A^{b}$ & 30.0 \\
\hline 4 & $10.9 \pm 0.9$ & $N D^{c}$ & Slight stimulation ${ }^{\mathrm{d}}$ & $N A^{b}$ \\
\hline 7 & $17.0 \pm 0.7$ & $148 \pm 35$ & $N A^{b}$ & 51.0 \\
\hline 8 & $1.4 \pm 0.1$ & $44.3 \pm 11$ & Toxic $^{e}$ & Toxic $^{e}$ \\
\hline 9 & $1.5 \pm 0.1$ & $2000 \pm 500$ & Toxic ${ }^{\mathrm{e}}$ & Toxic $^{\mathrm{e}}$ \\
\hline 10 & $70.2 \pm 2.3$ & $N D^{c}$ & $N A^{b}$ & 12.3 \\
\hline 11 & $70.2 \pm 2.3$ & $N D^{c}$ & $N A^{b}$ & $N A^{b}$ \\
\hline
\end{tabular}

Abbreviations: EGF, epidermal growth factor; PRL, prolactin.

aEGF- or PRL-mediated phosphorylation of ERK1/2 after 15 min determination as described in Supplementary Information.

bNo activity was observed up to $100 \mu \mathrm{m}$.
b

cNot detectable. Activity was either not detected up to $100 \mu \mathrm{m}$ or reliable standard derivations were not attainable.

dStimulated activity was found to be $\sim 150 \%$ at $100 \mu \mathrm{m}$

eToxicity to cells abrogated accurate data acquisition.

${ }^{13} \mathrm{C}$ NMR (125 MHz, $\mathrm{CDCl}_{3}$ ), see Table 1; MALDI-FTMS (positive ion), $[\mathrm{M}+\mathrm{Na}]^{+}$ion at $m / z 643.38151$ for $\mathrm{C}_{35} \mathrm{H}_{56} \mathrm{O}_{9}$ (calcd for $\left.[\mathrm{M}+\mathrm{Na}]^{+}, 643.38165\right)$.

Experimental procedures for cytotoxicity and ERK1/2 phosphorylation assays as well as ${ }^{1} \mathrm{H}$ and ${ }^{13} \mathrm{C}$ NMR data and spectra for $\mathbf{1}$ and $\mathbf{2}$ are provided as Supplementary Information.

\section{ACKNOWLEDGEMENTS}

We thank the Analytical Instrumentation Center of the School of Pharmacy, University of Wisconsin-Madison, USA for providing support in obtaining MS and NMR data and the University of Wisconsin Paul P Carbone Comprehensive Cancer Center SMSF for assistance with the activity analyses. This work was supported in part by the NIH grant CA113297 (BS), T32 GM08349 (KCC), the Wisconsin Alumni Research Foundation and the Chinese Ministry of Education 111 Project B08034 (YD).

1 Werner, G., Hagenmaier, H., Albert, K., Kohlshorn, H. \& Drautz, H. The structure of the bafilomycins, a new group of macrolide antibiotics. Tetrahedron Lett. 24, 5193-5196 (1983).

2 Werner, G. et al. Metabolic products of microorganisms. 224, bafilomycins, a new group of macrolide antibiotics production, isolation, chemical structure and biological activity. J. Antibiot. 37, 110-117 (1984).

3 Kretschmer, A., Dorgerloh, M., Deeg, M. \& Hagenmaier, H. The structures of novel insecticidal macrolides: bafilomycins D and E, and oxohygrolidin. Agric. Biol. Chem. 49, 2509-2511 (1985).

4 Carr, G. et al. Bafilomycins produced in culture by Streptomyces spp. Isolated from marine habitats are potent inhibitors of autophagy. J. Nat. Prod. 73, 422-427 (2010).

5 Ndejouong, B. et al. Hygrobafilomycin, a cytotoxic and antifungal macrolide bearing a unique monoalkylmaleic anhydride moiety, from Streptomyces varsoviensis. J. Antibiot. 63, 359-363 (2010).

6 Wilton, J. H., Hokanson, G. C. \& French, J. C. PD 118576: a new antitumor macrolide antibiotic. J. Antibiot. 38, 1449-1452 (1985).
7 Frändberg, E. et al. Streptomyces halstedii $\mathrm{K} 122$ produces the antifungal compounds bafilomycin B1 and C1. Can. J. Microbiol. 46, 753-757 (2000).

8 Goetz, M. A., Mccormick, P. A., Monaghan, R. L. \& Ostlind, D. A. L-155,175: a new antiparasitic macrolide fermentation, isolation and structure. J. Antibiot. 38, 161-168 (1985).

9 Vanek, Z., Mateju, J. \& Curdova, E. Immunomodulators isolated from microorganisms. Folia Microbiol. 36, 99-111 (1991).

10 Bowman, E. J., Siebers, A. \& Altendorf, K. Bafilomycins: a class of inhibitors of membrane ATPases from microorganisms, animal cells, and plant. Proc. Natl Acad. Sci. USA 85, 7972-7976 (1988).

$11 \mathrm{Knops,} \mathrm{J.} \mathrm{et} \mathrm{al.} \mathrm{Cell-type} \mathrm{and} \mathrm{amyloid} \mathrm{precursor} \mathrm{protein-type} \mathrm{specific} \mathrm{inhibition} \mathrm{of} A \beta$ release by bafilomycin A1, a selective inhibitor of vacuolar ATPases. J. Biol. Chem. 270, 2419-2422 (1995).

12 Saurin, A. J., Hamllet, J., Clague, M. J. \& Penington, R. Inhibition of mitogen-induced DNA synthesis by bafilomycin A1 in Swiss 3T3 fibrobasts. Biotechnol. J. 313, 65-69 (1996).

13 Huang, S. et al. Erythronolides $\mathrm{H}$ and $\mathrm{I}$, new erythromycin congeners from a new halophilic actinomycete Actinopolyspora sp. YIM90600. Org. Lett. 11, 1353-1356 (2009).

14 Huang, S. et al. Discovery and total synthesis of a new estrogen receptor heterodimerizing actinopolymorphol A from Actinopolymorpha rutilus. Org. Lett. 12, 3525-3527 (2010).

15 Powell, E. et al. Identification and characterization of a novel estrogenic ligand actinopolymorphol A. Biochem. Pharmacol. 80, 1221-1229 (2010).

16 Huang, S. et al. Cycloheximide and congeners as inhibitors of eukaryotic protein synthesis from endophytic actinomycetes Streptomyces sps. YIM56132 and YIM56141. J. Antibiot. 64, 163-166 (2011).

17 Moon, S., Hwang, W., Chung, Y. R. \& Shin, J. New cytotoxic bafilomycin C1-amide produced by Kitasatospora cheerisanensis. J. Antibiot. 56, 856-861 (2003).

18 Beyenbach, K. W. \& Wieczorek, H. The V-type $\mathrm{H}^{+}$ATPase: molecular structure and function, physiological roles and regulation. J. Exp. Biol. 209, 577-589 (2006).

19 Von Zastrow, M. \& Sorkin, A. Signaling on the endocytic pathway. Curr. Opin. Cell Biol. 19, 436-445 (2007).

20 Carver, K. C., Arendt, L. M. \& Schuler, L. A. Complex prolactin crosstalk in breast cancer: new therapeutic implications. Mol. Cell. Endocrinol. 307, 1-7 (2009).

21 Hynes, N. E. \& MacDonald, G. ErbB receptors and signaling pathways in cancer. Curr. Opin. Cell Biol. 21, 177-184 (2009).

22 Presley, J. F., Mayor, S., McGraw, T. E., Dunn, K. W. \& Maxfield, F. R. Bafilomycin A1 treatment retards transferrin receptor recycling more than bulk membrane recycling. J. Biol. Chem. 272, 13929-13936 (1997).

Supplementary Information accompanies the paper on The Journal of Antibiotics website (http://www.nature.com/ja) 